\title{
Efficient dam break flood simulation methods for developing a preliminary evacuation plan after the Wenchuan Earthquake
}

\author{
Y. Li ${ }^{1,2}$, J. H. Gong ${ }^{1,2}$, J. Zhu ${ }^{3}$, L. Ye ${ }^{1}$, Y. Q. Song ${ }^{4}$, and Y. J. Yue ${ }^{5}$ \\ ${ }^{1}$ State Key Laboratory of Remote Sensing Science, Institute of Remote Sensing Applications, Chinese Academy of Sciences, \\ Beijing 100101, China \\ ${ }^{2}$ Zhejiang-CAS Application Center for Geoinformatics, ZheJiang 314100, China \\ ${ }^{3}$ Southwest-jiaotong University, Chengdu 610031, China \\ ${ }^{4}$ College of Urban and Environmental Science, Tianjin Normal University, Tianjin 300387, China \\ ${ }^{5}$ Research Center for Eco-Environmental Sciences, Chinese Academy of Sciences, Beijing 100185, China
}

Correspondence to: J. H. Gong (jhgong@irsa.ac.cn)

Received: 14 September 2011 - Revised: 25 November 2011 - Accepted: 28 November 2011 - Published: 11 January 2012

\begin{abstract}
The Xiaojiaqiao barrier lake, which was the second largest barrier lake formed by the Wenchuan Earthquake had seriously threatened the lives and property of the population downstream. The lake was finally dredged successfully on 7 June 2008. Because of the limited time available to conduct an inundation potential analysis and make an evacuation plan, barrier lake information extraction and real-time dam break flood simulation should be carried out quickly, integrating remote sensing and geographic information system (GIS) techniques with hydrologic/hydraulic analysis. In this paper, a technical framework and several key techniques for this real-time preliminary evacuation planning are introduced. An object-oriented method was used to extract hydrological information on the barrier lake from unmanned aerial vehicle (UAV) remote sensing images. The real-time flood routine was calculated by using shallow-water equations, which were solved by means of a finite volume scheme on multiblock structured grids. The results of the hydraulic computations are visualized and analyzed in a 3-D geographic information system for inundation potential analysis, and an emergency response plan is made. The results show that if either a full-break or a half-break situation had occurred for the Chapinghe barrier lake on 19 May 2008, then the Xiaoba Town region and the Sangzao Town region would have been affected, but the downstream towns would have been less influenced. Preliminary evacuation plans under different dam break situations can be effectively made using these methods.
\end{abstract}

\section{Introduction}

Floods and landslides are among the most widespread natural hazards on Earth (Hong et al., 2007). Barrier lakes are caused by external substances blocking a river and are usually induced by earthquakes, landslides, debris flows, moraines, coulees of volcanic eruptions, or moving dunes, among others (Zuo, 1990; Liu et al., 2009). Barrier lakes have cumulative potential risk because of the loose components of soil and rocks and the increasing reservoir storage capacity. Schuster and Costa (1986) reported that half of all landslide dams fail within 10 days based on a study of 63 cases from the literature, and a dam burst often brings significant flooding casualties to the downstream residents (Liu et al., 2009). Because of time and resource limitations (Bitelli et al., 2004) and the rapid changes that occur in barrier lakes, it is always a great challenge to collect information for hazard mitigation in a timely manner because proper actions must be performed within a limited amount of time (Dong et al., 2011). Today, the application of remote sensing techniques for flood studies is receiving considerable attention (Amini, 2010). Development in this field has evolved from optical to radar remote sensing (Shailesh, 2004; Taylor et al., 2010; Taubenböck et al., 2011). However, the earthquake under study occurred in the middle of the rainy season; thus, accurate and timely acquisions, which are extremely important owing to the fast rising water level on daily basis, cannot be achieved using the traditional remote sensing techniques under cloudy weather. Moreover, the geomorphic phenomena were complex and therefore require sustained, concentrated and up-to-date observations of the barrier lake at high 

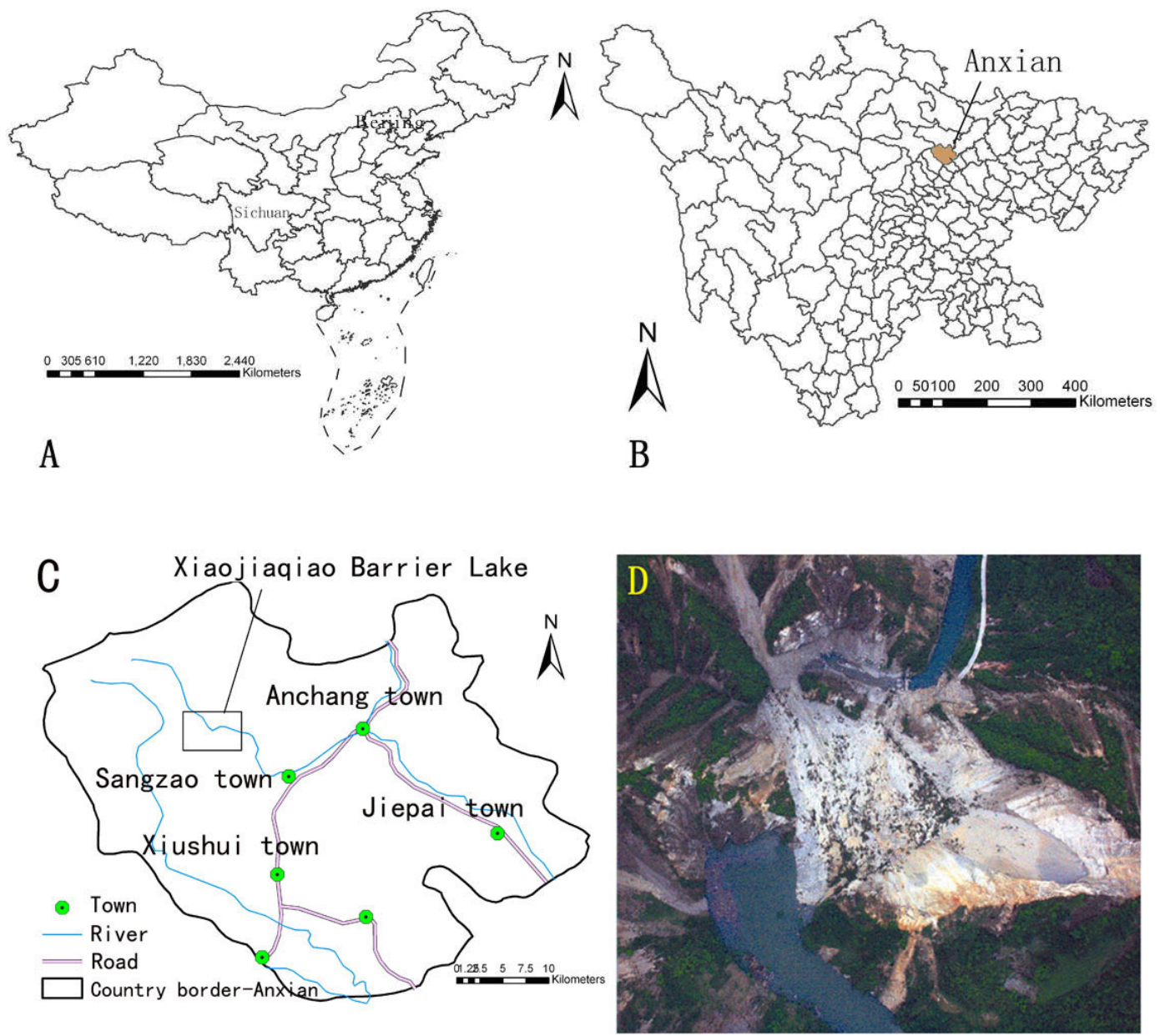

Fig. 1. Location of the study area: (a) Map of China, in which the annotated area is Sichuan province. (b) Map of Sichuan, in which the annotated area is Anxian. (c) Map of Anxian, in which the annotated area is the Xiaojiaqiao barrier lake. (d) A UAV photo of the Xiaojiaqiao barrier lake.

spatial resolution in cloudy weather. The technology of unmanned aerial vehicle (UAV) remote sensing can quickly detect changes in disaster information at the mesoscale without the effect of bad or cloudy weather and with a spatial resolution of at least $0.2 \mathrm{~m}$ (Li et al., 2009). The UAV played a crucial role in the Wenchuan Earthquake relief operations.

Although UAV remote sensing techniques can conveniently acquire information about a barrier lake in a timely manner, they are insufficient for providing on their own all of the dynamic information about a key dammed lake. Over the last few decades, the application of GIS (geographic information system) in flood risk mapping has proven to be a valuable tool for visualization, modeling and predictions (Sarkkila, 2001; Longley et al., 2006; Evans et al., 2007; Stanchev et al., 2009). In 3-D GIS, when UAV images are overlayed with high-resolution DEM data, a rich set of thematic flood data can be extracted and explored. A 3-D dynamic dam break flood simulation can be carried out under the support of various hydraulic and hydrological modeling techniques to efficiently assist decision-making and evacuation plans. Today, there is a consensus that GIS tools, which can integrate remote-sensing techniques with hydrological and geomorphologic parameters, provide a good platform to combine, manipulate, and analyze information for the rapid and efficient determination of potential flood areas (Youssef et al., 2011). However, few works describe the efficient collaboration between high-resolution remote sensing information extraction techniques and 3-D virtual flood routine calculations and simulation techniques.

The Wenchuan Earthquake $\left(M_{\mathrm{L}}=8.0\right)$ occurred on 12 May 2008. This earthquake resulted in more than 69000 casualties, as reported by the Chinese government (2008) (Ehrlich et al., 2009). It was reported that 34 barrier lakes were formed throughout the basin (Chen et al., 2008). The Tangjiashan and Xiaojiaqiao barrier lakes were the two largest and have since been dredged. For the sake of the safety of the downstream residents, the government made evacuation plans that were used to evacuate the 


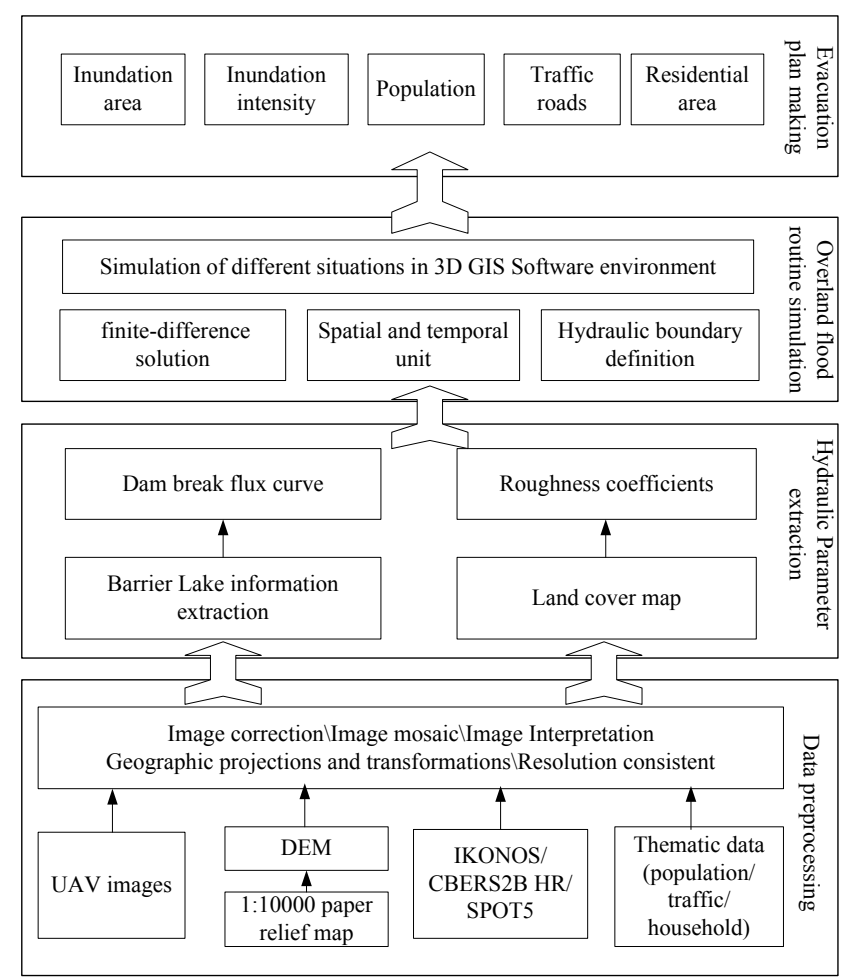

Fig. 2. Technical framework for dam break flood simulation and preliminary planning.

downstream residents of the Tangjiashan barrier lake. However, these evacuation plans were primarily made qualitatively or half-quantitatively, and they lack the scientific support of dam-burst flood routine simulation. In this paper, an efficient flood simulation and hazard evaluation technique framework that combines high-resolution remote sensing, GIS, virtual reality and hydrological models is presented. Several key techniques are introduced, such as an objectoriented classification method for hydrological information extraction, a dam break flow calculation method, and the calculation and simulation of flood routine procedures. All of these techniques worked well in the case study of the Xiaojiaqiao barrier lake, and a preliminary evacuation plan was developed.

\section{Site description and technical framework}

An'xian County is located in the southwest of Mianyang City, Sichuan Province, China, between $31^{\circ} 20^{\prime} \mathrm{N} \sim 31^{\circ} 50^{\prime} \mathrm{N}$ and $104^{\circ} 00^{\prime} \mathrm{E} \sim 104^{\circ} 45^{\prime} \mathrm{E}$, with an area of $1404 \mathrm{~km}^{2}$. The Xiaojiaqiao dammed lake was located at the upstream of the Chaping River in An'xian County (Fig. 1), and its catchment area was approximately $154.81 \mathrm{~km}^{2}$. This lake was the second largest dammed lake formed in the Wenchuan Earthquake. Because the dam body was made of detritus, it was an

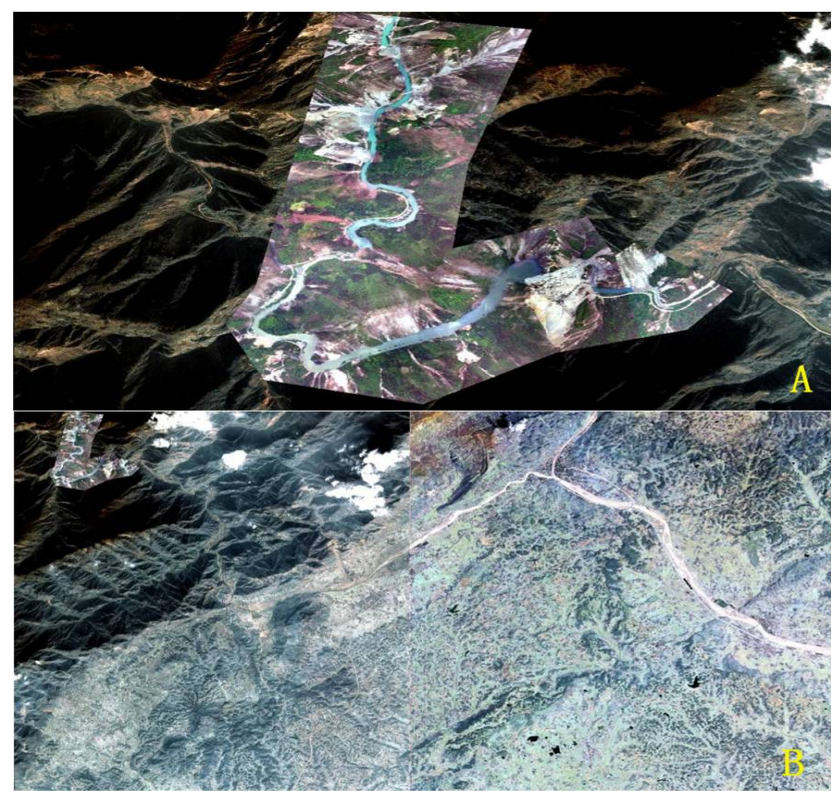

Fig. 3. (a) The UAV remote sensing image after the mosaic. (b) The IKONOS image.

extremely dangerous dammed lake. As reported by the local water authority, the failure of the Xiaojiaqiao dammed lake would have affected 6 towns (Xiaoba, Sangzao, Anchang, Huangtu, Huahai and Jiepai), 45 villages, 7 communities and the lives of 114000 people and their property. In addition, six key enterprises and two major traffic arteries were also threatened.

After the earthquake, UAV images with a spatial resolution of $0.2 \mathrm{~m}$ were acquired on 19 May 2008. Multisource remote sensing images before and after the earthquake were also collected, including an IKONOS image (26 December 2008), a SPOT-5 (10 November 2006), and a CBERS2B HR (27 June 2008). A terrain map covering the study area at a scale of 1:10000 was collected from the Bureau of Surveying and Mapping of Sichuan Province. The population, residential region, road and facility data were provided by the Anxian water authority.

The technical framework for the dam break flood simulation and preliminary plan making is shown in Fig. 2. Multisource remote sensing images, DEM and thematic data were coupled with GIS, remote sensing and hydraulic tools to provide a good platform for flood simulation and evacuation planning.

\section{Data preprocessing}

The contour map with $10 \mathrm{~m}$ intervals was scanned, georeferenced to the UTM Zone 49 projection and WGS_1984 coordinate system and then digitized. Finally, a digital elevation model (DEM) with $10 \mathrm{~m}$ resolution was generated. 


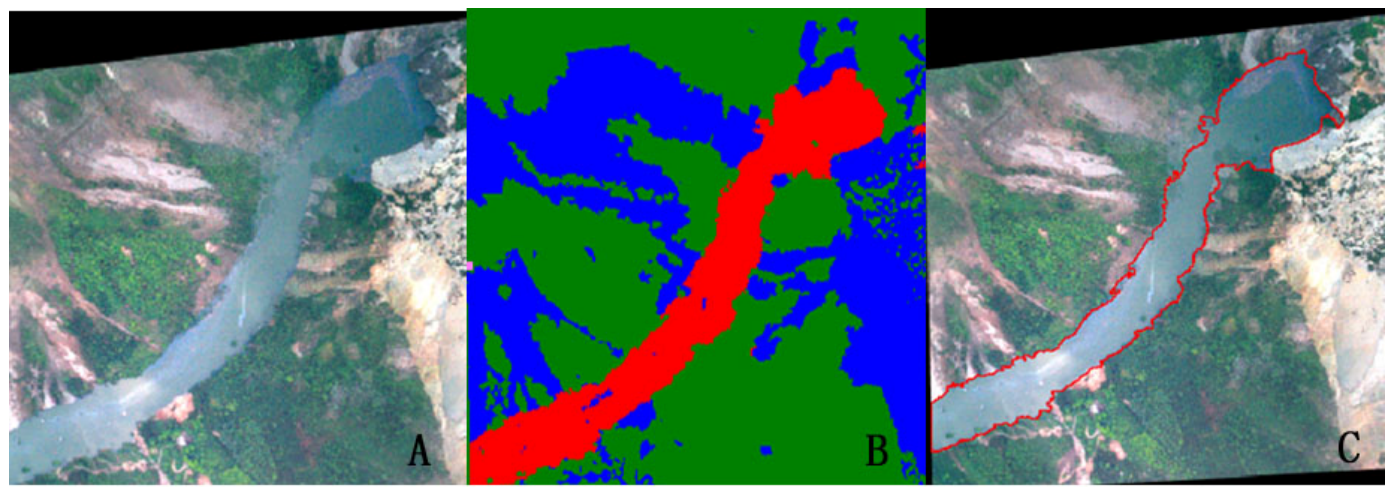

Fig. 4. The boundary extraction of the dammed lake. (a) The original UAV image. (b) The classification results of the UAV image. (c) The extracted scope of the water region.

The UAV images have a ground resolution of $0.2 \mathrm{~m}$ and are obtained by using a non-metric camera. The image sequence number is sorted with strips. The locations of the photos are calculated by the index file. Because the study area is a region containing hills and ravines, it was essential to remove relief displacement. Image orthorectifications for UAV images are implemented using ground control points and the above generated DEM. Then, the SIFT (Scale-Invariant Feature Transform) algorithm is used to find images with the same name as the point of the match between the image and the stitching.

In the geometric correction process, images are corrected to an IKONOS satellite image of $1 \mathrm{~m}$ spatial resolution with a geometric error of less than one pixel. The UAV remote sensing image after the mosaic (Fig. 3a) was overlapped with the IKONOS image (Fig. 3b).

Data containing geographic information on the population, the residential areas, the roads and facilities were preprocessed to obtain standard GIS vector layers, which are ready for inundation analysis.

\section{Methodology}

\subsection{Barrier lake information extraction}

UAV remote sensing images contain high-spatial-resolution information about the important targets. The traditional pixel-based remote sensing classification techniques have proven to be unsuitable for information extraction from highspatial-resolution images. Instead, the object-oriented classification method can fully explore the spectral, spatial and textural attributes of high-spatial-resolution images. This method can extract various characteristics in images, such as vehicles, buildings, roads, rivers, bridges, lakes, and fields. Thus, the object-oriented classification method was herein employed to explore the barrier lake information in the UAV images.
ENVI 4.7EX software was adopted to perform the objectoriented classification. The workflow obeys a segmentationmerge-refine-computing-attributes-classification. In this paper, a segmentation threshold of $60 \%$ and a merge threshold of $99 \%$ were adopted. The boundary of the water region could be quickly extracted from the UAV images. Figure 4a shows the original UAV image, and Fig. $4 \mathrm{~b}$ shows the resulting classified UAV image. In this image, the barrier lake region is shown in red; the vegetation plot is shown in green; and the bare land is shown in blue. Figure $4 \mathrm{c}$ shows the extracted scope of the water region.

The Xiaojiaqiao barrier lake boundary of 19 May 2008 was obtained, which is shown in Fig. 5a. We can see that points $\mathrm{A}$ and $\mathrm{B}$ are two river blocks formed by the earthquake-induced landslide and that the Xiaojiaqiao barrier lake is formed owing to the obstructions. The area of the extracted dammed lake was overlapped with the DEM data, and the dataset is shown in the 3-D scene (Fig. 5b). The white region represents the dammed lake. The contour line of $765 \mathrm{~m}$ was overlapped with the barrier lake, and the outlines match well. The water depth of each pixel were then calculated according to the outline of the dammed lake and the DEM data. The water depth at the dam of the barrier lake $\left(H_{0}\right)$ was $31.5 \mathrm{~m}$. The volume of the dammed lake $(W)$ could be obtained by summing up the calculated volumes of each pixel, and result was approximately $2800000 \mathrm{~m}^{3}$. The outlet of the barrier lake $(B)$ was measured by using the spatial measurement function of ArcGIS 9.2, and it was found to be approximately $133 \mathrm{~m}$.

\subsection{Dam break flow calculation}

The extracted information about the barrier lake, which was introduced in Sect. 4.1, contains the valley width of the dam site $(B)$, the water depth of the dam site $\left(H_{0}\right)$, and the volume of the dammed lake $(W)$. The calculation of the dam break considers the most severe condition, which corresponds to the full break of the barrier lake. Thus, the breach size $\left(b_{m}\right)$ 
Table 1. The half-experiential data adopted.

\begin{tabular}{lllllll}
\hline$t / T$ & 0 & 0.05 & 0.1 & 0.2 & 0.3 & 0.4 \\
$Q / Q_{m}$ & 1.0 & 0.62 & 0.48 & 0.34 & 0.26 & 0.207 \\
$t / T$ & 0.5 & 0.6 & 0.7 & 0.8 & 0.9 & 1.0 \\
$Q / Q_{m}$ & 0.168 & 0.13 & 0.094 & 0.061 & 0.03 & $Q_{0} / Q_{m}$ \\
\hline
\end{tabular}

Table 2. Flood arrival time at different locations for the Xiaojiaqiao landslide (Unit: s).

\begin{tabular}{lrrr}
\hline $\begin{array}{l}\text { Break } \\
\text { Type }\end{array}$ & $\begin{array}{r}\text { Dam failure } \\
\text { duration (s) }\end{array}$ & $\begin{array}{r}\text { Flood arrival } \\
\text { Xiaoba town }\end{array}$ & $\begin{array}{c}\text { Flood arrival } \\
\text { Sangzao town }\end{array}$ \\
\hline Full break & 589 & 2580 & 4380 \\
Half break & 488 & 3360 & 6420 \\
\hline
\end{tabular}

adopts a value equal to $B$. Because the downstream water was shallow before the collapse, Saint-Venant equations were adopted to calculate the instantaneous peak flow at the breach $\left(Q_{m}\right)$.

The calculation of the discharge process line is highly complex, and it can be simplified to four parabolas. The emptying time of the dammed lake $(T)$ can be calculated from Eq. (2), where $K$ is the coefficient with a value equal to 4 . According to the half-experiential data (Table 1) published in Technical Guidelines for emergency disposal of landslide lake (Ministry of Water Resources of China, 2009), the discharge process line can be obtained with $Q_{m}$ and $T$ as follows:

$Q_{m}=\frac{8}{27} B \sqrt{g} H_{0}^{\frac{3}{2}}$

$T=K \frac{W}{Q_{m}}$

Supposing the occurrence of full-break situation, according to formulas (1) and (2), the calculation result of the peak flow at the breach $\left(Q_{m}\right)$ is $21810 \mathrm{~m}^{3} \mathrm{~s}^{-1}$, and the result of the emptying time of the dammed lake $(T)$ is $589 \mathrm{~s}$. If the half-break situation occurs (the upper part of the dam breaks, shown in Fig. 6a), then the calculation result of $Q_{m}$ is $13264 \mathrm{~m}^{3} \mathrm{~s}^{-1}$, and the result of $T$ is $488 \mathrm{~s}$. The dam break flux curves for the full-break and half-break scenarios are shown in Fig. $6 b$.

\subsection{Overland flow routing}

The finite-difference solution (Liu, 1991) of the Saint-Venant equations is adopted in this study to perform downstream overland flow routing with inputs from the dam break flow calculation. The governing equations are depth-averaged continuity and dynamic wave equations. The simplified numerical equations are expressed as Eqs. (3)-(5).

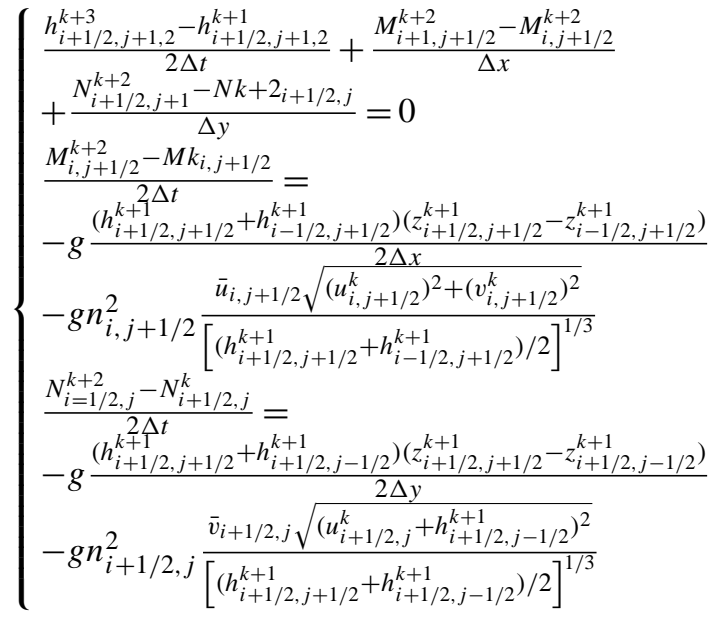

where $\mu$ and $\nu=$ the averaged velocity components along the $\mathrm{x}$ - and y-coordinates; $t=$ time; $h=$ water depth; $z=$ water line; $n=$ roughness rate; and $g=$ gravitational acceleration. $\mathrm{M}$ and $\mathrm{N}=$ the width-averaged flux along the $\mathrm{x}$ and y-coordinates. That is, $M=\mu \times h$, and $N=v \times h$.

The dam break flux is decomposed to 2 dimensions and used as the inflow conditions. This flux changes over time after the barrier lake breaks. Performing overland flow routing often requires a large amount of hydrological and geographical data. Based on the DEM data with $10 \mathrm{~m}$ resolution, the same resolution is adopted to perform simulations. The coordinate and elevation of each grid was extracted from DEM data. The land-use map is acquired from the classification result of the IKONOS image, and the roughness coefficients of each grid were calculated from land-use information and the table of Manning's roughness coefficient values (Engman, 1986).

The simulation domain of overland flow routing for the Xiaojiaqiao barrier lake case was discretized with uniform grids having sizes of $10 \mathrm{~m} \times 10 \mathrm{~m}$. There were 165480 grids accounting for $16.55 \mathrm{~km}^{2}$ of the downstream lowlands of the Xiaojiaqiao barrier lake. Under different dam failure durations, Figs. 7 and 8 show the simulated results of full break and half break, respectively, for the Xiaojiaqiao barrier lake.

In the full-break situation, the flood reaches the town of XiaoBa 43 min after the dam break, while it reaches Sangzao town $1 \mathrm{~h}$ and $13 \mathrm{~min}$ after the dam break. In the halffailure situation, the flood reaches XiaoBa town at $56 \mathrm{~min}$ and Sangzao town at $1 \mathrm{~h}$ and $47 \mathrm{~min}$ after the dam break.

Because the ground surface and channel slopes after Xiaoba town become smoother than the upstream of XiaoBa creek, broader inundation extents and deeper inundation depths were found. The computed maximum inundation depths downstream of Xiaojiaqiao are listed in Table 2. Furthermore, the amount of time available for evacuation, which can be estimated from the propagation time of flood waves from the peak flood wave at the site, is critical to knowing how many lives can be saved in such natural disasters. 


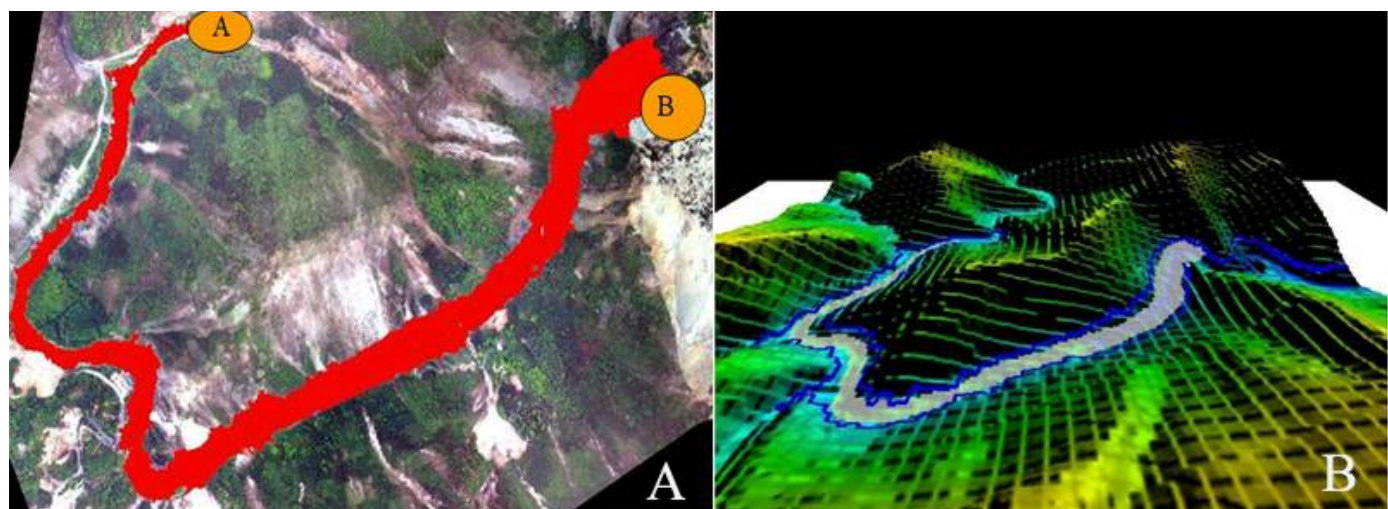

Fig. 5. (a) Boundary of the Xiaojiaqiao barrier lake on 19 May 2008. (b) The boundary of the dammed lake overlapped with a $765 \mathrm{~m}$ contour line in the 3-D scene.

Table 3. Maximum inundation depths at different locations for the Xiaojiaqiao landslide (Unit: $\mathrm{m}$ ).

\begin{tabular}{lrrrrrr}
\hline $\begin{array}{l}\text { Break } \\
\text { Type }\end{array}$ & Zongcanwusuo & Xiaobaxiang & $\begin{array}{r}\text { Xiaobazhen } \\
\text { fulin }\end{array}$ & $\begin{array}{r}\text { Shangqing } \\
\text { cun }\end{array}$ & $\begin{array}{r}\text { Xiangxi } \\
\text { cun }\end{array}$ & $\begin{array}{r}\text { Sangzao } \\
\text { town }\end{array}$ \\
\hline Full break & 14.56 & 7.2 & 6.5 & 3.64 & 1.68 & 0.46 \\
Half break & 6.78 & 2.89 & 3.61 & 0.5 & 0.62 & 0 \\
\hline
\end{tabular}
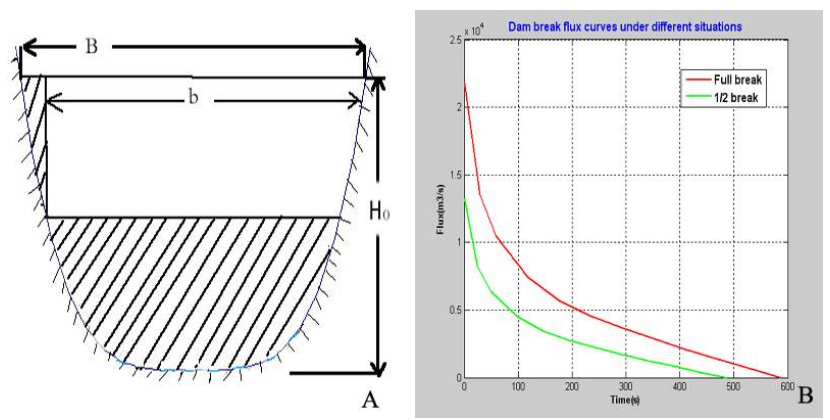

Fig. 6. (a) Half-break situation. (b) Dam break discharge process line calculation result.

With GIS-assisted inundation potential analysis, people living downstream will know when to evacuate and where to go once a landslide dam really fails.

\section{Inundation potential analysis and evacuation planning}

Once the barrier lake is formed and discovered, preparations for emergency actions must be taken before a crisis occurs. An underestimated disaster will result in a great loss of lives and property, while an overestimated disaster will cause unnecessary panic and make the affected region vulnerable to chaos. Flood risk mapping is an essential element of flood risk management and risk communication (Merz, 2010). The
Table 4. Population distribution in inundation areas.

\begin{tabular}{lrrr}
\hline Place name & Latitude & Longitude & Population \\
\hline Guanxincun & 31.595 & 104.318 & 2256 \\
Baiguoping & 31.620 & 104.323 & 861 \\
Zhongxincun & 31.587 & 104.326 & 1623 \\
Wufucun & 31.633 & 104.311 & 1573 \\
Zhongfucun & 31.630 & 104.332 & 623 \\
Huangyangcun & 31.622 & 104.305 & 1162 \\
Lianghecun & 31.599 & 104.286 & 1278 \\
Lizhicun & 31.591 & 104.377 & 1586 \\
Yunfengcun & 31.601 & 104.376 & 1640 \\
Feilongcun & 31.609 & 104.393 & 2370 \\
Yuxicun & 31.590 & 104.385 & 1130 \\
Haishuicun & 31.576 & 104.362 & 2019 \\
Xiangxicun & 31.613 & 104.366 & 1909 \\
Shangqingcun & 31.605 & 104.344 & 830 \\
Qiniucun & 31.618 & 104.337 & 845 \\
Tongqiancun & 31.653 & 104.350 & 934 \\
Xiaobazhenfulin & 31.597 & 104.323 & 313 \\
Sangzao town & 31.600 & 104.358 & 4650 \\
Anchang town & 31.642 & 104.419 & 49333 \\
Zongcanwusuo & 31.601 & 104.314 & Unavailable \\
\hline
\end{tabular}

GIS-assisted inundation potential analysis performed in this study is expected to provide a correct and accurate analysis of the inundation potential and to help people and government agencies when planning emergency response measures. 


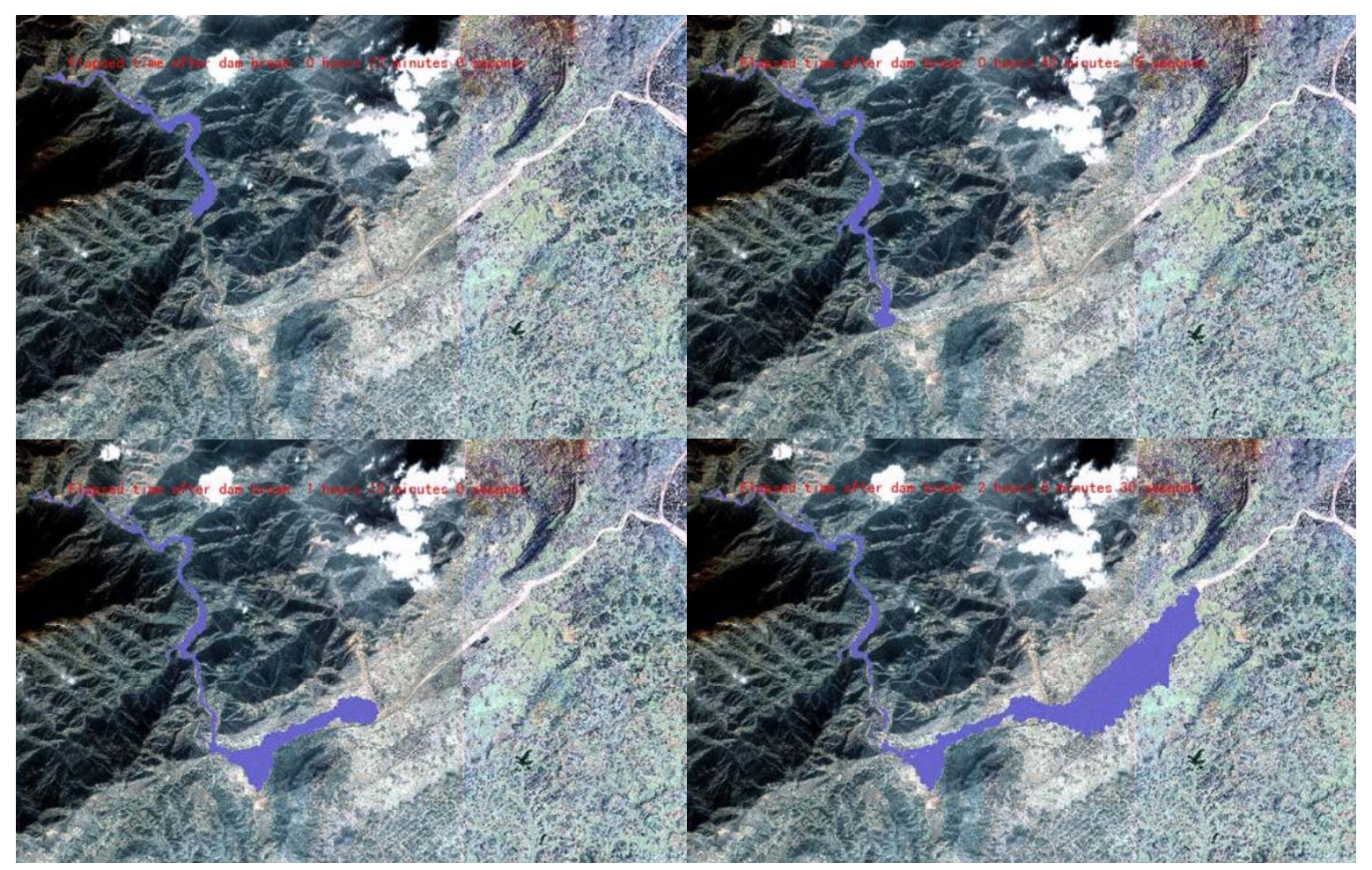

Fig. 7. Flood routing simulation results in 3-D visualization (5.19 full break).

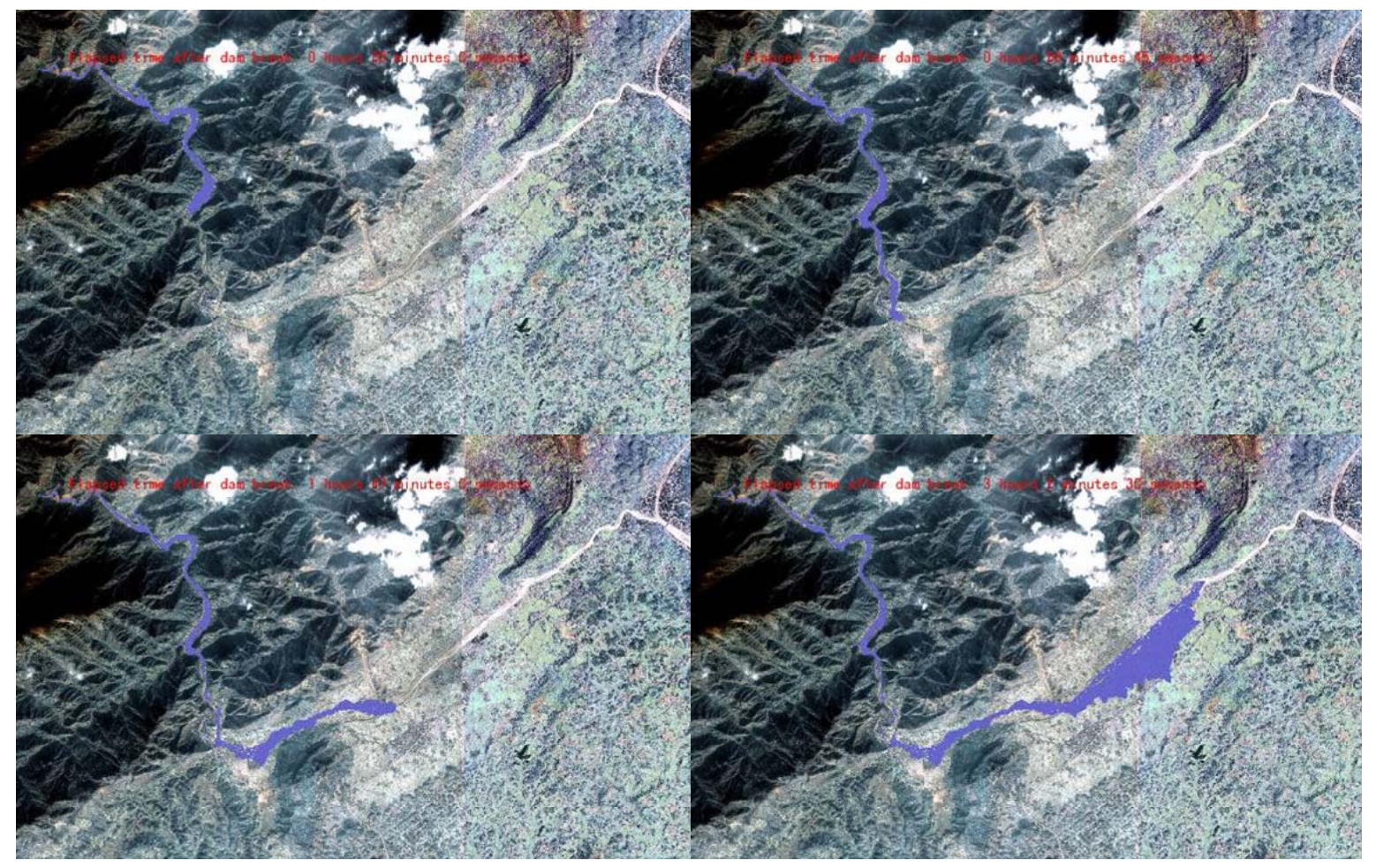

Fig. 8. Flood routing simulation results in 3-D visualization (5.19 half break). 


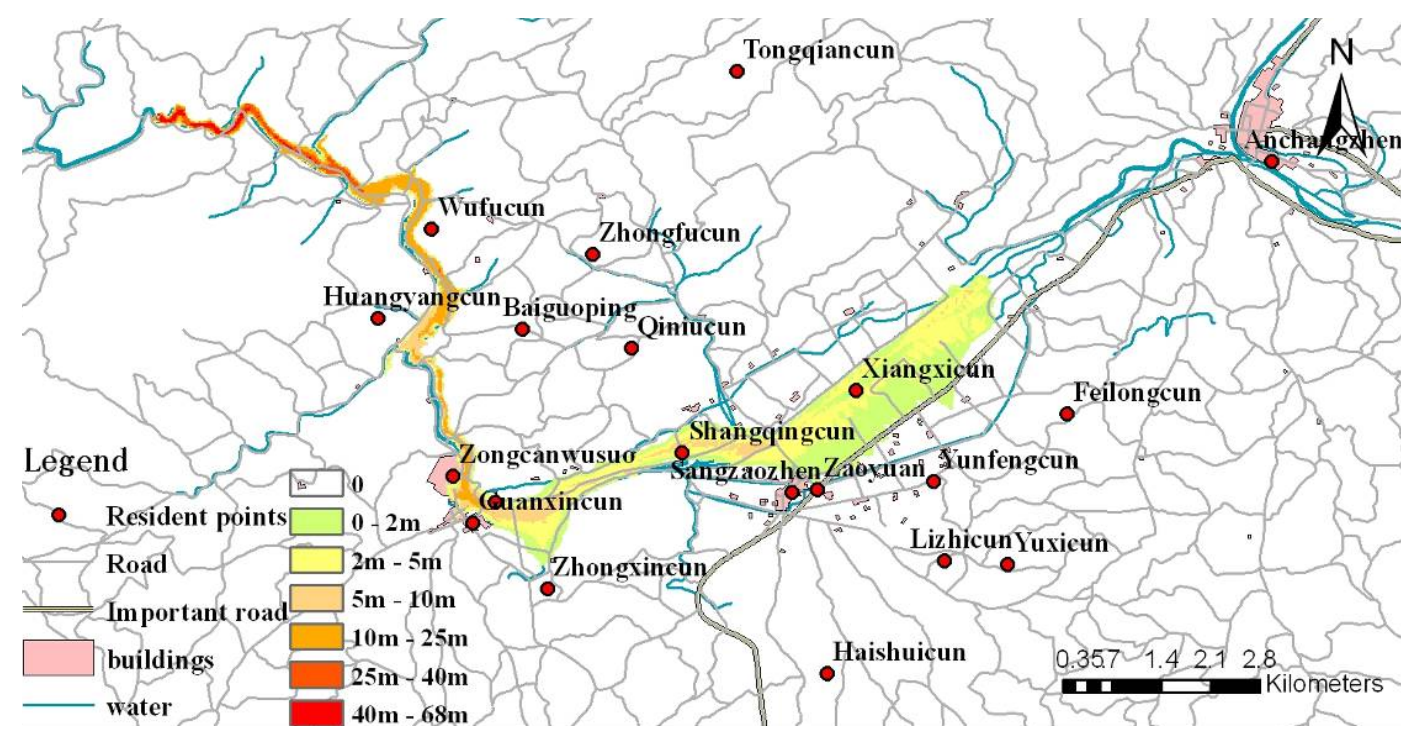

Fig. 9. Flood inundation potential analysis (5.19 full break).

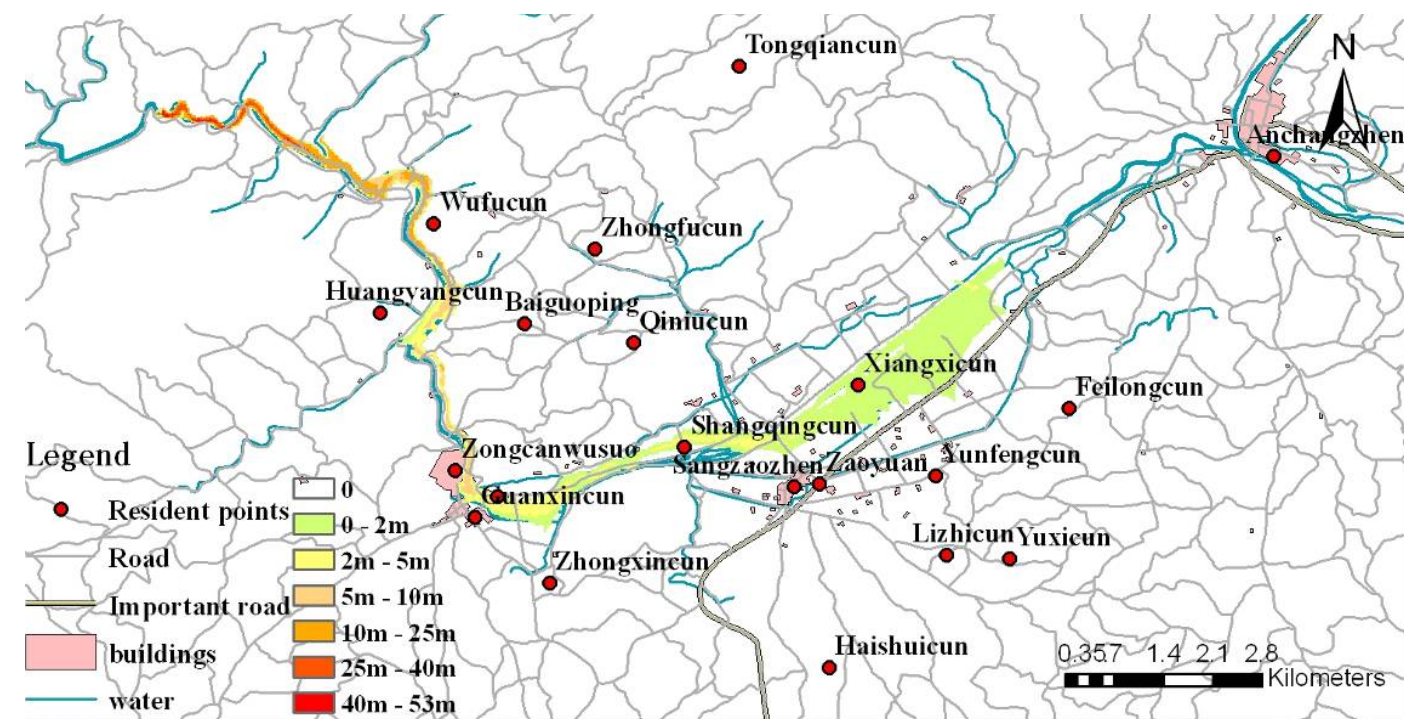

Fig. 10. Flood inundation potential analysis (5.19 half break).

Different levels of possible inundation areas can be obtained by mapping the simulation results of overland flow routing with various digital data, including streets, rivers, buildings, and counties, in different dam failure scenarios.

The maximum inundation depths at important locations are listed in Table 3. The population distribution in inundation areas is listed in Table 4. The depth maps, which are overlapped with elements such as population, resident region, roads and facilities, are shown in Figs. 9 and 10.

It can be seen that in the full-break situation, the residential points Zongcanwusuo (the fifth research institute of general staff headquarters), Xiaobazhenfulin and Anxincun would be completely submerged, and the water depth could reach
$14.56 \mathrm{~m}$ and $7.2 \mathrm{~m}$, respectively. The villages of Shangqingcun and Xiangxicun are also in the inundation area, and the maximum water depth reaches $3.64 \mathrm{~m}$ and $1.68 \mathrm{~m}$, respectively. The affected population exceeds 5300. In addition, the population of Zongcanwusuo is unavailable. Sangzao town and the S105 road would also be affected.

In the half-break situation, the maximum water depth at Zongcanwusuo and Xiaobazhenfulin would exceed $2.5 \mathrm{~m}$, while Guanxincun would be less affected. The flood would also reach the villages of Shangqingcun and Xiangxicun, where the water depth would be $0.5 \mathrm{~m}$ and $0.62 \mathrm{~m}$, respectively, while Sangzao town and the S105 road would be less affected. The affected population is near the value for the 


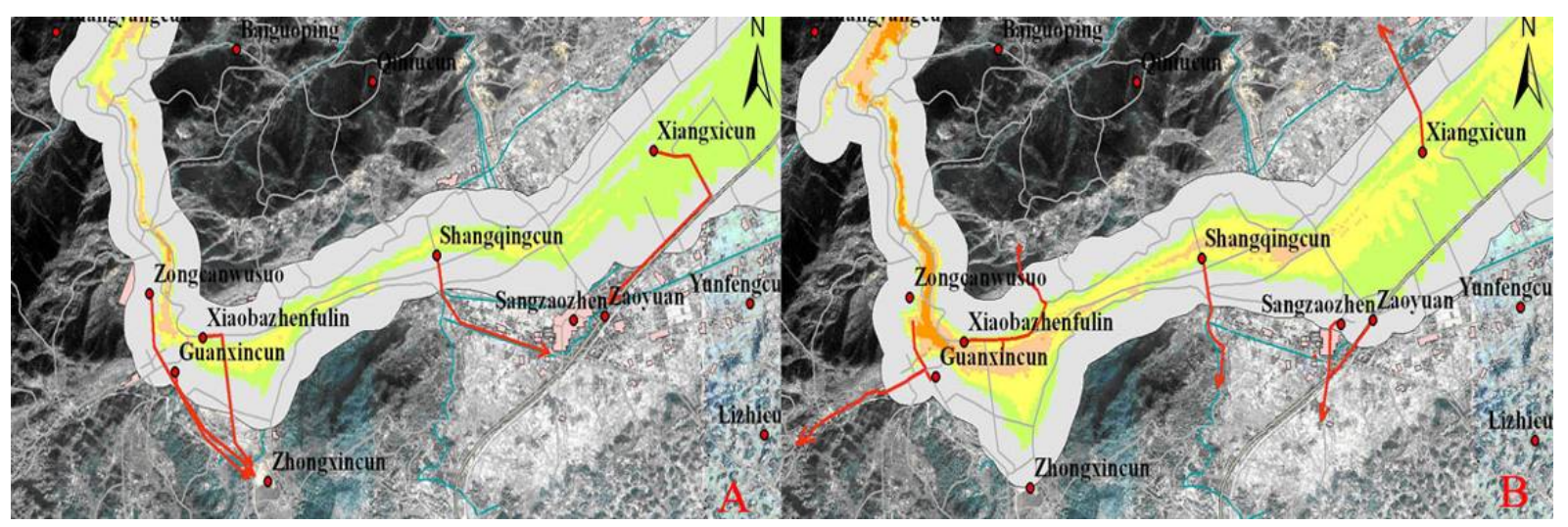

Fig. 11. Evacuation planning: (a) 5.19 half break (b) 5.19 full break.

Table 5. Advantages of each step.

\begin{tabular}{lll}
\hline & Techniques in this paper & Traditional techniques \\
\hline Image acquisition & $\begin{array}{l}\text { Takes one or two hours, the UAV images } \\
\text { can be acquired at any time during the } \\
\text { day }\end{array}$ & $\begin{array}{l}\text { Takes several days (restricted by the tem- } \\
\text { poral resolution of satellite remote sens- } \\
\text { ing and the image quality) }\end{array}$ \\
Barrier lake information extraction & Faster and more accurate & Moderate efficiency and accuracy \\
$\begin{array}{l}\text { Overland flow simulation } \\
\text { Inundation potential analysis }\end{array}$ & $\begin{array}{l}\text { Takes less than half an hour, the analysis } \\
\text { and planning can be supported by GIS } \\
\text { visualization platform }\end{array}$ & $\begin{array}{l}\text { Lacks the support of integrated GIS visu- } \\
\text { alization platform, low efficiency in data } \\
\text { management and analysis }\end{array}$ \\
\hline
\end{tabular}

full-break situation, but the extent of damage is much less because of the shallower submerged depth.

A risk buffering region $(300 \mathrm{~m})$ was generated with the inundation area, and a simple evacuation plan was made according to the path layer, which is shown in Fig. 11. Figure 11a shows the evacuation plan in the half-break situation, where the population in five places needs to be evacuated: Zongcanwusuo, Guanxincun, Xiaobazhenfulin, Shangqincun and Xiangxicun. In the half-break situation, the nearest residential points to the 5 places are Zhongxincun and Anchang towns. The refugees would have timely access to these locations via roads and could be effectively relocated.

Figure 11b shows the evacuation plan in the full-break situation. It can be seen that Zhongxincun and Anchang town are also in the risk buffering region. Thus, in this situation, the refugees need to evacuate farther away. This paper adopts path data to provide a plan for the refugees to quickly escape from the dangerous region.

\section{Conclusions and discussion}

The landslide-induced barrier lake, which occurs as a result of a combination of flooding and landslide, makes the acquisition and management of hazard information dangerous, difficult and requires multiple tasks. Today, remote-sensing information acquired and processed in real time can have a great impact in dealing with inaccessible regions. Most works adopt only remote-sensing information for qualitative or half-quantitative hazard evaluation analysis. Few works integrate remote-sensing techniques, hydrological modeling, GIS visualization and analysis to provide experts with new platforms for data management and decision-making. In the evacuation scenarios in the aftermath of Wenchuan Earthquake, the planning lacked the scientific support of spatial information techniques.

In this study, a technical framework for dam break flood simulation and preliminary plan making is proposed that couples multisource remote sensing images, DEM and thematic data with GIS, remote sensing and hydraulic tools. Using these techniques, a succession of actions, including the dambreak flood routine simulation, inundation potential analysis and evacuation planning can be effectively accomplished 
with fine precision. All of these steps, from the acquisition of UAV images to the simulation and analysis of inundation potentials of the dam break, are active and performed automatically. The advantages in each step are shown in Table 5. From the simulation results, the inundation depths, extent and emergency response time for the downstream residents were found to be greatly affected by the dam failure situation. For the sake of safety, it is necessary to make evacuation plans for the full-break situation.

When there is a lack of real dam-break flood routine data, the techniques in this paper provide only an evacuation plan, but the validation is difficult. Meanwhile, periodically updating the DTM data is important for accurate and effective dam break simulation when there is large surface displacement caused by a destructive earthquake such as the Wenchuan earthquake. Thus, the automatic 3-D reconstruction of DTM using UAV remote-sensing images can be combined with the steps in this paper to provide much more accurate and timely information in the future.

Acknowledgements. This research is supported by the National Natural Science Foundation of China (41101363, 40871181), the Key Knowledge Innovative Project of the Chinese Academy of Sciences 315 (KZCX2-EW-318), and the Basic Research Program of China, 973 Program, No. 2007CB714402.

Edited by: M. E. Contadakis

Reviewed by: P. Anagnostopoulos and M. Vafeiadis

\section{References}

Amini, J.: A method for generating floodplain maps using IKONOS images and DEMs, Int. J. Remote Sens., 31, 2441-2456, 2010.

Bitelli, G., Camassi, R., Gusella, L., and Mognol, A.: Image change detection on urban areas: the earthquake case. Proceedings of the 20th International Archives of the Photogrammetry, Remote Sensing and Spatial Information Sciences, 12-23 July 2004, Istanbul, Turkey, 692 pp., 2004.

Cheng, G. W., Wang, X. D., He, X. B., Fan, J. H., and Fan, J. R.: Outburst risk of barrier lakes in Sichuan, China, J. Mountain Sci., 5, 189-193, 2008.

Dong, J. J., Tung, Y. H., Chen, C. C., Liao, J. J., and Pan, Y. W.: Logistic regression model for predicting the failure probability of a landslide dam, Eng. Geol., 117, 52-61, 2011.

Ehrlich, D., Guo, H. D., Molch, K., Ma, J. W., and Pesaresi, M.: Identifying damage caused by the 2008 Wenchuan earthquake from VHR remote sensing data, Int. J. Digi. Earth, 2, 309-326, 2009.

Engman, E. T.: Roughness coefficients for routing surface runoff, J. Irrig. Drain. Eng, 112, 39-53, 1986.

Evans, S. Y., Gunn, N., and Williams, D.: Use of GIS in Flood Risk Mapping. National Hydrology Seminar GIS (Geographic Information Systems) in Hydrology Applications-Modelling-Data Issues (Tullamore, Ireland), 1-12, 2007.
Hong, Y., Adler, R., and Verdin, J.: Use of 21 st century satellite remote sensing technology in natural hazard analysis, Nat. Hazards, 43, 165-166, 2007.

Li, Y., Gong, J. H., Hong, Y., and Song, Y. Q.: An UAV remote sensing image-supporting technique for scenes' multi-quadtree organization and inter-source dispatch, High Technology Letters (Chinese), 19, 971-976, 2009.

Liu, L. Y., Wu, Y. H., Zuo, Z. L., Chen, Z. C., Wang, X. X., and Zhang, W. J.: Monitoring and assessment of barrier lakes formed after the Wenchuan earthquake based on multitemporal remote sensing data, J. Appl. Remote Sens., 3, 031665, doi:10.1117/1.3153915, 2009.

Liu, S. K., Li, X. P., Li, S. G., and Yu, T. Y.: Numerical Simulation of Flood Routing in the Xiaoqinghe Flood Plain, Adv. Water Sci., 2, 188-193, 1991.

Longley, P. A., Goodchild, M. F., Maguire, D. J., and Rhind, D. W.: Geographical Information Systems and Science, John Wiley and Sons LTD, England, 517 pp., 2006.

Merz, B., Kreibich, H., Schwarze, R., and Thieken, A.: Review article "Assessment of economic flood damage", Nat. Hazards Earth Syst. Sci., 10, 1697-1724, doi:10.5194/nhess-10-16972010, 2010.

Ministry of Water Resources of China: Technical Guidelines for emergency disposal of landslide lake, SL 451-2009, available at: http://ishare.iask.sina.com.cn/f/19913587.html (last access: 11 November 2011), 2009.

Sarkkila, J.: Digital terrain modelling for flood analysis and impact assessment in emergency action planning. RESCDAM (Development of rescue actions based on dam- break flood analysis) Final Report, Appendix 6, available at: http://www.ymparisto.fi/ download.asp?contentid=12412\&lan=en, 2001.

Schuster, R. L. and Costa, J. E.: A perspective on landslide dams, in: Landslide Dam: Processes Risk and Mitigation, edited by: Schuster, R. L., American Society of Civil Engineers, Geotechnical Special Publication, 3, 1-20, 1986.

Shailesh, K. S.: Analysis of uncertainties in digital elevation models in flood modelling, MS thesis, ITC, The Netherlands, 2004.

Stanchev, H., Atanas, P., and Margarita, S.: 3-D GIS Model for Flood Risk Assessment of Varna Bay Due to Extreme Sea Level Rise, J. Coast. Res., 56, 1597-1601, 2009.

Taubenböck, H., Wurm, M., Netzband, M., Zwenzner, H., Roth, A., Rahman, A., and Dech, S.: Flood risks in urbanized areas - multi-sensoral approaches using remotely sensed data for risk assessment, Nat. Hazards Earth Syst. Sci., 11, 431-444, doi:10.5194/nhess-11-431-2011, 2011.

Taylor, P.: A method for generating floodplain maps using IKONOS images and DEMs, Int. J. Remote Sens., 31, 2441-2456, 2010.

Youssef, A. M. and Pradhan, B.: Flash flood risk estimation along the St. Katherine road, southern Sinai, Egypt using GIS based morphometry and satellite imagery, Environ. Earth Sci., 62, 611623, 2011.

Zuo, D. K.: A Modern Dictionary of Geography, the Commercial Press, Beijing, 1990 (in Chinese). 